\title{
Attitudinal Determinants of Aberrant Driving Behaviors in Pakistan
}

\author{
Zahara Batool and Oliver Carsten
}

The aberrant behavior of drivers is regarded as the most significant contributory factor to traffic accidents in Pakistan. This research was conducted on the premise that personal attitudes were key determinants of driving behaviors. Consequently, the research attempted to identify the key sociocognitive determinants of aberrant driving. To do this, a quantitative study that used an attitudinal questionnaire (inspired by the theory of planned behavior and a modified driver behavior questionnaire) was conducted in the city of Lahore, Pakistan. The study obtained self-reports of attitudes, norms, perceived control, and opinions of drivers regarding a number of intentional road traffic violations and enforcement. The responses to the statements in the questionnaires were first factor analyzed to identify underlying attitudinal and behavioral constructs. Later, following a cluster analysis technique, the attitudinal constructs were used to classify drivers into four distinct groups: the autonomous, the opportunists, the regulators, and the risk averse. Sociodemographic characteristics and behavioral constructs of these groups were also studied. The results indicated that the behaviors of drivers could be interpreted in relation to their attitudes and were partly influenced by the drivers' sociodemographic characteristics. Attitudes toward enforcement and compliance with rules specifically appeared to be the strongest determinants of Pakistani drivers' behavior. In particular, the results indicate that being affluent, female, and a student negatively influenced driving behaviors.

In Pakistan, drivers are held responsible for the majority of traffic crashes. The government and peer-reviewed literature suggest that the traffic safety records for the country are worsening. It has been argued that traffic problems are intensified and consequently pose a threat to road safety because of poor driving practices and the ever-increasing number of vehicles on the country's roads. Overall, traffic injuries make up the largest proportion of injuries in the country (1). The proportion of road user error involved in crashes in Pakistan is estimated to be $91 \%$ (2). However, despite the gravity of the situation, the country lacks adequate empirical research related to road safety. The underlying factors that precede the deviant behaviors have not yet been scientifically assessed for the country. The lack of such knowledge is attributable to the difficulty of designing and implementing behavior-changing interventions. This also exacerbates the difficulties of achieving sustainable results through ongoing road safety campaigns and local projects. This research set out to examine pre-

Z. Batool, Department of Transportation Engineering and Management, University of Engineering and Technology, Lahore, Pakistan. O. Carsten, Institute for Transport Studies, University of Leeds, United Kingdom. Corresponding author: Z. Batool, zaharabatool14@gmail.com.

Transportation Research Record: Journal of the Transportation Research Board, No. 2602, Transportation Research Board, Washington, D.C., 2016, pp. 52-59. DOI: 10.3141/2602-07 crash phenomena, focusing on human factors in road traffic crashes. With the help of traffic psychology, it attempts to understand the factors that result in poor driving behaviors in Pakistan.

\section{THEORETICAL FRAMEWORK}

Over the years, it has been established that changes in driver behavior offer the largest opportunities for harm reduction (3). These behaviors are likely to be influenced by the attitudes of drivers toward road safety (4). Therefore, it has been suggested that understanding the attitudinal and motivational components attached to aberrant behaviors is important to efforts to improve driving behaviors [e.g., Parker (5) and Glendon (6)]. In the broadest sense of functionality, attitudes facilitate behavioral adaptation to the environment (7).

Many studies have used established psychological theories of attitude-behavior relations, such as the theory of planned behavior (TPB), to understand drivers' behavior (8). The theory states that volitional behavior is founded on intention, which is a function of three cognitive components: attitudes, subjective norms, and perceived behavioral control. The model has generated a great deal of interest within contemporary literature (9). A voluminous TPB-inspired literature testifies to its heuristic value (10).

As for Pakistan, no work has been identified that explores attitudes and behaviors of drivers with the help of a comprehensive theoretical framework. Thus, this research took guidelines from the TPB framework to evaluate Pakistani drivers' attitudes toward traffic safety and to attempt to identify key attitudinal determinants of aberrant driving behaviors. However, it is not within the scope of this paper to assess the predictive utility of each TPB construct to behavior because the theory is not applied rigidly.

Along with attitudes, the road safety literature suggests that many other factors, including situational and cultural factors, level of enforcement, and drivers' demographic and socioeconomic characteristics, also influence their behavior. These factors are associated with the frequency with which violations are committed. For example, variables such as age, gender, and exposure are all known to be correlated with accident involvement [e.g., Iversen and Rundmo (9), Ward and Lancaster (11)]. However, the effect of these variables on driving behavior varies in intriguing ways in different parts of the world. This research investigated the relationship between some of these variables and drivers' propensity to commit violations in the context of Pakistan. The motivation for this investigation was enhanced because of a marked difference between various social classes (in terms of education, income, and occupational status) in the country. These differences are easily observable on the public roads, which are used by drivers of various classes of society. The act of driving and the vehicle that is driven can be used as a display 
of personal status. This research not only explored which sociodemographic characteristics exacerbate risky attitudes and behaviors but also assessed the types of violations committed by various groups under certain driving conditions.

\section{ANALYTICAL METHODS}

A leading concern about psychological research these days is the manipulation of the results by the researchers to find what they wanted to find (12). Particularly, for the development of traffic safety strategies, findings are traditionally drawn on the basis of data reduction correlation techniques such as factor analysis, which can investigate only one relationship at one time (13). However, as noted, multiple factors shape drivers' behavior. To address these limitations, rather than investigating the effect of one dimension on one type of driving behavior at a time, or preclassifying groups on the basis of personal circumstances or sociodemographic characteristics that cannot be changed, this study used cluster analysis to classify groups of people (or drivers) on the basis of the combined effect of multiple sociocognitive factors that are involved in shaping driving behavior and that can be changed through persuasion. It is simply the act of defining meaningful subgroups of individuals or objects (14). The technique was adopted in the hope of alleviating stereotyping. The study attempted to look at multifaceted driving behaviors in combination with several factors, not in isolation. It was hoped that the identification of groups who held specific attitudes associated with specific risk behaviors could help develop more adjusted and effective traffic safety interventions. Thus, the principal aim of this study was to contribute to an understanding of the attitudinal and behavioral dimensions of Pakistani drivers' behavior toward road safety (with reference to road traffic violations), together with the underlying influence of sociodemographic factors.

\section{METHODOLOGY}

\section{Survey Questionnaire}

\section{Attitudinal Measures}

A number of measurement tools have recently been developed to examine individuals' driving behaviors. However, the driver attitude questionnaire developed on the basis of the theoretical approach of the TPB remains the predominant tool to assess general motorists' driving attitudes and outcomes (15). In this research, preliminary guidelines for developing an attitudinal questionnaire (AQ) were borrowed from the driver attitude questionnaire. To make the questionnaire more relevant and specific to the driving population of Pakistan, a qualitative study was conducted in the exploratory stage of this research [for more details, see Batool et al. (16)]. On the basis of the qualitative study, a 58-item AQ was developed. All items used a five-point Likert scale to express levels of agreement (a higher score on any item indicates a safer attitude).

The questionnaire attempted to cover drivers' attitudes toward different types of intentional traffic violations (e.g., speeding, no seat belt or helmet, driving under the influence of alcohol or drugs). It also tapped their opinions toward enforcement, different sociocultural and physiological factors, and social and personal norms. Collectively, these statements were called "attitudes toward road safety."

\section{Behavioral Measures}

Road safety literature suggests that traffic violations are the most risky type of aberrant behavior. The violations are rooted in motivational factors, contribute to the most risky road safety situations, and are committed because of drivers' attitudes (17). It is thus important to study drivers' behavior with respect to intentional violations. With this specific focus, the study collected maximum information about the most deviant type of aberrant behavior, using a 12-item modified version of the driver behavior questionnaire (DBQ) taken from Lawton et al. (18). The questionnaire was further adapted on the basis of the insight of an earlier study (16). With the incorporation of local, Pakistan-specific factors, a 29-item extended version of the DBQ was developed. The questions can logically be divided into highway code violations and aggressive-behavior violations. The questions mainly touched on behaviors related to speeding, following too closely, driving after drinking or taking drugs, overtaking, driving while distracted, use of seat belt or helmet, and vehicle fitness. Participants were asked to indicate how frequently they engaged in these behaviors by rating on a six-point scale with endpoints 0 (never) and 6 (nearly all the time). The higher the score, the more aberrant was the behavior.

\section{Sociodemographic Measures}

The questionnaire collected information related to the socioeconomic and demographic characteristics of the participants such as age, gender, education, and income. It also recorded some other drivingrelated information, including number of years the driving license had been held, weekly distance driven, and the frequency of accidents and near misses in the past 6 months.

\section{Study Procedure and Participants}

Before the study was conducted, ethics approval was obtained from the University of Leeds. The risk-assessment exercise was done using university protocols. A pretest study exercise was carried out to assess the efficacy and design of the questionnaire. This testing, on a sample of 20 drivers, helped ( $a$ ) to identify potential problems stemming from the planned data collection procedure and $(b)$ to couch questions in language that was understandable by and relevant to the potential participants. The feedback received was then applied to create a final version of the questionnaire to make it suitable for the general population. The study was conducted in Urdu and recruited drivers from different densely populated areas of Lahore, Pakistan. Ten student surveyors from Punjab College University and the University of Engineering and Technology, Lahore, who had been trained and informed about the intent of the study, conducted the survey.

With a total number of 438 participants, the major groups covered in the survey were professional and novice drivers, business and leisure commuters, housewives, and elderly people. The categorization was meant $(a)$ to fairly represent the diverse driving population of Lahore and $(b)$ to examine the extent of attitudinal and behavioral differences within substrata of the society without restricting the study with respect to sociodemographic composition. As the prime rationale of this study was to avoid a priori classification, participants were approached randomly. An on-street intercept technique was adopted and used at business and shopping centers (including 
high-income, middle-income, and low-income areas), public and private universities, public transport stands, and residential areas (including high-income, middle-income, and low-income areas). The diversified study locations were selected to combat potential bias in the sample. The refusal rate was not quantified but overall it was noted to be high among businessmen and very low among public transport drivers. Participants who found the questionnaire difficult to understand were helped to complete the questionnaires by the surveyors. On average, the time required to complete the questionnaire was estimated to be 15 minutes. A bar of chocolate was presented to respondents as a token of appreciation.

\section{ANALYSES}

\section{Descriptive Analysis}

A univariate descriptive analysis was made to assess the representativeness of different groups in the sample. On some indicators, the sample characteristics appeared to be somewhat similar to or comparable with the general characteristics of the urban population of Pakistan. For example, the sample was predominantly composed of relatively young drivers (up to 34 years old), just like the national population (76.9\% and 64\%, respectively). The types of vehicles driven by the sample population were also comparable to general statistics for Pakistan: car drivers (40\% and 37\%, respectively), motorcyclists (40.7\% and 50\%, respectively) and professional drivers (19.2\% and $16 \%$, respectively). Likewise, the statistics about marital status of the sample and of the population were comparable: unmarried (56\% and $45.31 \%$, respectively), married ( $40 \%$ and $50.55 \%$, respectively), separated or divorced $(1.9 \%$ and $4.10 \%$, respectively). The mean number of near misses for the study's drivers in the past six months was 2.72; of accidents in that time, 1.98. On average, participants had held a driving license for 8.43 years and drove $363.47 \mathrm{~km}$ weekly.

\section{Segmentation Analysis}

The study divided the driving population of Pakistan on the basis of their attitudes toward road safety in three distinct steps. Briefly, in Step 1, 58 attitudinal items (variables) were factor analyzed to reduce the variables into a smaller, manageable number of factors (dimensions). For this, principal component analysis with quartimax rotation was used. The technique makes no prior assumptions concerning an underlying causal structure of data (14). The analysis results indicated that Pakistani drivers have six distinctive and indicative attitudinal dimensions. These were named as attitudes toward rule breaking, careless driving, enforcement, the influence of peer pressure, and regard for personal safety and for other road users. All these factors exclusively measured a single underlying construct with high internal consistency $(\alpha>.5)$. They can be treated as stand-alone results to underpin good or bad driving behaviors (Table 1).

In Step 2, the extracted factors (grouping variables) were treated as a set of uncorrelated latent variables to perform cluster analysis. This step attempted to identify naturally occurring homogeneous groups of drivers in the sample (segments or clusters). A two-stage cluster analysis approach, agglomerative hierarchical clustering and nonhierarchical $k$-means clustering analysis, was adopted. Hierarchical clustering revealed the number and structure of the clusters that represented the data most effectively and were used as initial cluster seeds in $k$-means analysis. Initially, a three- to six-cluster solution was considered reasonable for the data. The hierarchical clustering method is advantageous for determining the number of clusters present. However, it cannot produce the optimal cluster solution pertaining to between-cluster heterogeneity because the method is unable to separate clusters created at previous steps. Thus, it is recommended to run a $k$-means cluster analysis after the number of clusters has been determined. For this, the centroids (i.e., the cluster center means) generated from the hierarchical analysis were used as a starting point (8). Thus, $k$-means cluster analysis calculated the most optimal cluster solution. The analysis produced four stable and distinguishable subgroups of drivers.

Later, multiple discriminant analysis was conducted as a penultimate stage of segmentation to validate and assess how well clustering computed the optimal solution. The analysis assessed the impact and weight of each identified attitudinal dimension in the formulation of the subgroups. The analysis confirms that the cluster analysis not only saliently used all latent variables in the attitudinal definition of the groups but classified more than $90 \%$ of subjects into their naturally occurring group.

Finally, in Step 3, the groups were interpreted and profiled in terms of their driving behaviors and sociodemographic characteris-

TABLE 1 Summary of Factor Analysis

\begin{tabular}{|c|c|c|c|c|}
\hline Factor & $\begin{array}{l}\text { Example Attitude Statement (variable loading most highly } \\
\text { on the factor) }\end{array}$ & $\begin{array}{l}\text { Number of Variables } \\
\text { Loading on Factor }\end{array}$ & Cronbach's $\alpha$ & $\begin{array}{l}\text { Variance } \\
\text { Explained }(\%)\end{array}$ \\
\hline $\begin{array}{l}\text { Rule compliance: attitudes } \\
\text { toward rule compliance }\end{array}$ & $\begin{array}{l}\text { People stopped by traffic wardens for changing lane without } \\
\text { using indicator are unlucky because lots of people do it. }\end{array}$ & 13 & .81 & 8.4 \\
\hline $\begin{array}{l}\text { Careful driving: taking care } \\
\text { in driving }\end{array}$ & $\begin{array}{l}\text { It is quite acceptable to drive a vehicle at night with poor } \\
\text { lights. }\end{array}$ & 6 & .74 & 6.6 \\
\hline $\begin{array}{l}\text { Enforcement: value of } \\
\text { enforcement }\end{array}$ & $\begin{array}{l}\text { I think traffic wardens should fine as many people as possible } \\
\text { who disregard stop lines at intersections. }\end{array}$ & 9 & .73 & 6.5 \\
\hline $\begin{array}{l}\text { Peer pressure: ability to } \\
\text { override peer pressure }\end{array}$ & $\begin{array}{l}\text { It is hard to remain calm and drive safely if everyone else is } \\
\text { not respecting your right-of-way. }\end{array}$ & 3 & .52 & 3.4 \\
\hline $\begin{array}{l}\text { Personal safety: regard for } \\
\text { personal safety }\end{array}$ & $\begin{array}{l}\text { Driving without a seatbelt or helmet does not necessarily } \\
\text { increase accident risk. }\end{array}$ & 3 & .52 & 3.3 \\
\hline $\begin{array}{l}\text { Road users regard: regard } \\
\text { for other road users }\end{array}$ & $\begin{array}{l}\text { For me to speed, blow the horn, or overtake to get ahead of } \\
\text { female drivers is satisfying. }\end{array}$ & 3 & .52 & 3.2 \\
\hline
\end{tabular}

NOTE: Total variation explained (after rotation $)=31.0 \%$. 
tics. An analysis of variance (ANOVA), post hoc multiple comparisons tests, and chi-square tests were run to identify the significant differences among the segments.

\section{Interpretation and Profiling}

\section{Attitudinal Profiling}

The clusters were labeled after their unique attitudinal profiles on the basis of a combination of mean scores they had on all six attitudinal factors (Table 2). Table 2 shows the results of using the Hochberg post hoc multiple means comparison test for A1, A3, A5, and A6, and Games-Howell for A2 and A4. Note that a high score (centroid elements $>0.40$ ) on a factor with either positive (favorable) or negative (unfavorable) orientation represents a strong association of the group on that particular construct.

Cluster $1(n=35,12.73 \%)$ emerged as a group of drivers who had the highest law-abiding attitudes (A1) and tended to appreciate careful driving (A2). Among the segments, the group had the highest mean scores on nine out of 13 attitudinal items of A1, and on two out of six items of A2. For example, this group discourages taking a chance now and then on roads, enjoys following traffic rules and regulations, and appreciates it if people are stopped by traffic wardens for changing lanes without using the turn indicator. However, at the same time, the group evolved as a group of "independent" drivers who do not appreciate the influence of external factors such as enforcement (A3) or peer pressure (A4), which can control their driving. The group is therefore termed "autonomous." However, to ensure undisrupted, free movement, the group is least likely to have regard for other road users (A6) or their own personal safety (A5).

The drivers in the smallest cluster, Cluster $2(n=18 ; 6.54 \%)$ reported the strongest intention of breaking the law (A1) and indicated the least favorable attitude toward enforcement (A3). For example, in this group's opinion, people should not be stopped for following too closely or improper lane changing. They favor taking revenge for impolite behaviors or running a red light. Likewise, the group does not appreciate being fined for disregarding stop lines or the strict enforcement of overtaking regulations on urban roads. Therefore, the group was labeled as "opportunists" who always keep seeking a chance to move ahead on the roads. Always look- ing for opportunities to get ahead, the group is careful (A2), as any disruption can interfere with their ability to maneuver. This group of drivers also appeared to be highly considerate toward other road users (A6).

Cluster 3 ( $n=142,51.64 \%)$, which emerged as the largest group of the study, was characterized by its highly favorable attitudes toward enforcement (A3). Among the segments, the group had highest mean scores on all nine attitudinal items of A1. For example, the group strongly favored traffic wardens' issuing fines to as many people as possible for disregarding stop lines. The group encouraged more stringent enforcement of rules and regulations related to overtaking, to the use of LCD TVs in vehicles, and to the use of mobile phones as well as vehicle safety standards. Therefore, this group was labeled "regulators." Although A1 does not have significant loading on the group (>.40), it is the only other noticeable dimension of this group, which indicates these drivers' low propensity to comply with the rules (A1).

Cluster 4 ( $n=80,29.09 \%)$ drivers are not in favor of stringent law enforcement (A3). They tend to condone careful driving (A2) and are likely to be affected by peer pressure (A4). For example, the group does not appreciate being fined for carrying goods or articles that are over a vehicle's capacity. This group's drivers think it is okay to ignore traffic signals or to drive with worn-out tires. They are likely to get angry and drive unsafely if other drivers do not respect their right of way. However, at the same time, the group significantly favors rule compliance (A1) and tends to feel that they should not break the rules if others do. They think it is easy to carry out traffic rules in practice. They also are willing to wait at traffic signals irrespective of long waiting times. Therefore, the group was labeled as "risk averse."

Figure 1 further displays the total mean scores of the segments on all attitude questionnaire items. It shows that, overall, the group called regulators reported the most favorable attitudes toward road safety by scoring highest. The regulators group was also found to be statistically different from the opportunists and the risk-averse group (Table 2). The opportunists hold the least favorable attitudes in the sample.

To summarize, cluster analysis was used to classify the sample driving population of Pakistan into four attitudinal segments: the autonomous, opportunists, regulators, and the risk averse. ANOVAs with post hoc comparisons made clear that the groups were significantly different from each other on all six attitudinal dimensions. The

TABLE 2 Mean Scores and Significant Differences of Clusters on Attitudinal Variables

\begin{tabular}{lccccr}
\hline Factor & $\begin{array}{c}\text { Autonomous } \\
\text { (Cluster 1) }\end{array}$ & $\begin{array}{l}\text { Opportunists } \\
\text { (Cluster 2) }\end{array}$ & $\begin{array}{l}\text { Regulators } \\
\text { (Cluster 3) }\end{array}$ & $\begin{array}{c}\text { Risk Averse } \\
\text { (Cluster 4) }\end{array}$ & F-Value \\
\hline Rule compliance (A1) & $\mathbf{. 5 8}^{a, b}$ & $-\mathbf{. 9 3}^{b, c, d}$ & $-.29^{a, c, d}$ & $\mathbf{. 4 6}^{a, b}$ & $24.55^{*}$ \\
Careful driving (A2) & $\mathbf{. 5 6}^{b, d}$ & $\mathbf{. 9 6}^{b, d}$ & $-.05^{a, c, d}$ &.$- \mathbf{4 3}^{a, b, c}$ & $19.39^{*}$ \\
Enforcement (A3) & $-.24^{a, b, d}$ & $-\mathbf{. 9 5}^{b, c}$ & $\mathbf{. 6 1}^{a, c, d}$ &.$- \mathbf{7 8}^{b, c}$ & $71.35^{*}$ \\
Peer pressure (A4) & $\mathbf{. 9 8}^{b, d}$ & $.33^{d}$ & $-.02^{c, d}$ & $-\mathbf{. 5 0}^{a, b, c}$ & $23.97^{*}$ \\
Personal safety (A5) & $-\mathbf{. 8 9}^{b, d}$ & -.28 & $.06^{c}$ & $.25^{c}$ & $14.28^{*}$ \\
Road users regard (A6) &.$- .9^{a, b, d}$ & $\mathbf{. . 5 2}^{b, c, d}$ & $-.01^{a, c}$ & $.03^{a, c}$ & $27.23^{*}$ \\
Total AQ score & 136.28 & $129.89^{b}$ & $137.70^{a, d}$ & $133.35^{b}$ & $4.26^{*}$ \\
\hline
\end{tabular}

NoTE: Boldface indicates significant values.

${ }^{a}$ Statistically different from Cluster 2 .

${ }^{b}$ Statistically different from Cluster 3.

${ }^{c}$ Statistically different from Cluster 1 .

${ }^{d}$ Statistically different from Cluster 4 .

$* p<.01$. 


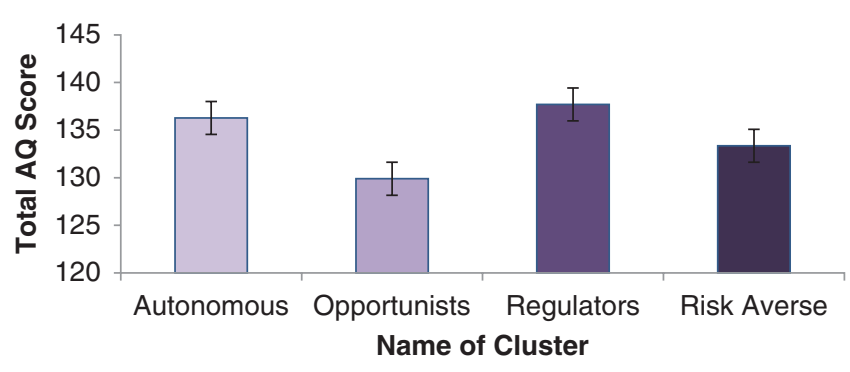

FIGURE 1 Relative comparison of self-reported total scores of groups on the $A Q$.

regulators had the most favorable and the opportunists had the least favorable attitudes toward road safety.

\section{Behavioral Profiling}

To examine the behavioral dimensions of the sample population, the DBQ data were subjected to principal component analysis with promax rotation. The analysis generated a four-factor solution. Each tapped an exclusive and highly reliable behavioral construct related to Pakistani drivers. The factors were labeled as measuring intimidating behavior by drivers, "being above the rules," "risk-prone infringements," and "assertion-this is my space." The study further explored the magnitude of these behaviors by attitudinal segments using ANOVAs with post hoc multiple comparisons. The behaviors of the groups were assessed on some other driving indicators as well, including total DBQ score, weekly distance driven, near misses, and accidents (Table 3). Table 3 shows the results of using the Hochberg post hoc multiple means comparison test for B1, B2, and B4, and Games-Howell for B3.

Figure 2 plots the total DBQ scores of the segments and reveals that although the groups reported different behaviors from each other, the differences were only slightly noticeable, unlike the overall attitudinal differences. Moreover, as was the case for the attitudinal profiles, the regulators were again found to be statistically different from

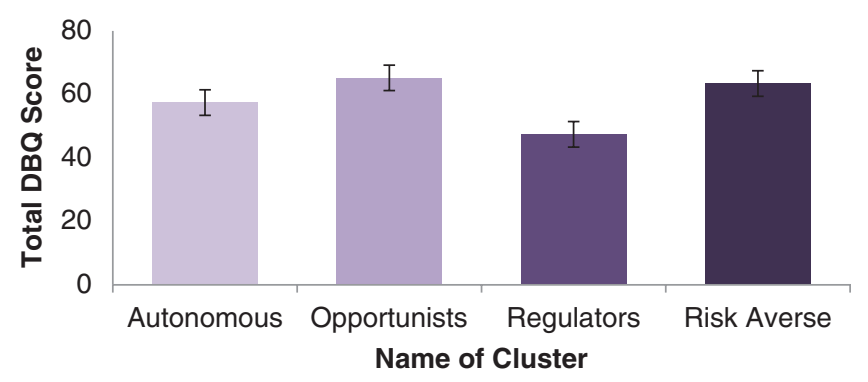

FIGURE 2 Relative comparison of self-reported total scores of groups on the DBQ.

opportunists and the risk averse in terms of their driving behaviors (Table 3).

\section{Sociodemographic Composition}

The final stage of the profiling identified the demographic and socioeconomic composition of the segments (Table 4). It showed that the attitudinal segments had varying compositions of sociodemographic characteristics.

\section{DISCUSSION OF RESULTS}

By producing four statistically meaningful attitudinal constructs, this paper expanded the previous findings of validity and appropriateness of the TPB. It supported exploring the various facets of drivers' attitudes, particularly in the Pakistani context. Each group was found to have a unique and meaningful combination of attitudinal characteristics. For example, an autonomous driver had significantly favorable attitudes toward rule compliance, careful driving, and a strong ability to override peer pressure. However, at the same time, this group of drivers did not value enforcement. They were also less likely to have regard for their own personal safety or for that of other road users. The phenomenon can be linked to their self-governing nature, which

TABLE 3 Behavioral Differences of Clusters

\begin{tabular}{lccccc}
\hline Behavioral Factor & $\begin{array}{l}\text { Autonomous } \\
\text { (Cluster 1) }\end{array}$ & $\begin{array}{l}\text { Opportunists } \\
\text { (Cluster 2) }\end{array}$ & $\begin{array}{l}\text { Regulators } \\
\text { (Cluster 3) }\end{array}$ & $\begin{array}{l}\text { Risk Averse } \\
\text { (Cluster 4) }\end{array}$ & $F$-Value \\
\hline Intimidating (B1) & -.08 &. $\mathbf{4 1}$ & $-.23^{a}$ & $.33^{b}$ & $5.65^{*}$ \\
Above rules (B2) & .22 & $\mathbf{. 4 5}^{b}$ & $-.24^{a, c}$ & $.31^{b}$ & $5.90^{*}$ \\
Infringements (B3) & .05 & .29 & $-.27^{a}$ & $.28^{b}$ & $5.04^{*}$ \\
Assertion (B4) & .00 & $\mathbf{. 4 9}^{b}$ & $-.28^{a, c}$ & $.35^{b}$ & $7.91^{*}$ \\
Total DBQ score & 57.43 & $65.22^{b}$ & $47.43^{a, c}$ & $63.44^{b}$ & $10.06^{*}$ \\
Weekly mileage (km) & 240.20 & 240.06 & $445.85^{a}$ & $255.19^{b}$ & $3.63^{* *}$ \\
Near misses & 1.77 & 2.61 & 2.66 & 2.38 & .663 \\
Accidents & 1.11 & 1 & 1.64 & 1.27 & .611 \\
\hline
\end{tabular}

NOTE: Superscripts show which mean scores of clusters are significantly different (at $p<.001$ and $p<.05)$ from other groups.

${ }^{a}$ Statistically different from Cluster 4 .

${ }^{b}$ Statistically different from Cluster 3.

${ }^{c}$ Statistically different from Cluster 2 .

$* p<.001 ; * *<<.05$. 
TABLE 4 Sociodemographic Characteristics of Segments

\begin{tabular}{|c|c|c|c|c|c|}
\hline Variable & Autonomous (\%) & Opportunists (\%) & Regulators (\%) & Risk Averse (\%) & In Sample (\%) \\
\hline \multicolumn{6}{|l|}{ Age $\left(\right.$ years) ${ }^{a}$} \\
\hline$\leq 19$ & 14.3 & 16.7 & 7.70 & 17.5 & 12.0 \\
\hline $19-34$ & 60.0 & 61.1 & 66.9 & 63.8 & 64.7 \\
\hline$\geq 35$ & 20.0 & 22.3 & 23.2 & 13.8 & 20.0 \\
\hline \multicolumn{6}{|l|}{ Income group $^{b}$} \\
\hline Lower income & 48.6 & 27.8 & 45.8 & 22.5 & 38.2 \\
\hline Middle income & 17.1 & 16.7 & 24.6 & 21.3 & 22.2 \\
\hline Higher income & 17.1 & 38.9 & 13.4 & 31.3 & 20.7 \\
\hline \multicolumn{6}{|l|}{ Gender $^{c}$} \\
\hline Male & 85.7 & 72.2 & 91.5 & 75.0 & 84.7 \\
\hline Female & 14.3 & 27.8 & 7.70 & 25.0 & 14.9 \\
\hline \multicolumn{6}{|l|}{ Marital status ${ }^{a}$} \\
\hline Single & 51.4 & 50.0 & 48.6 & 66.3 & 54.2 \\
\hline Married & 40.0 & 38.9 & 49.3 & 28.8 & 41.5 \\
\hline Separated or divorced & 2.90 & 5.60 & 0.70 & 2.60 & 1.8 \\
\hline \multicolumn{6}{|l|}{ Housing tenure type ${ }^{a}$} \\
\hline Own or buying & 51.4 & 55.6 & 41.5 & 58.8 & 48.7 \\
\hline Rent & 22.8 & 27.8 & 27.4 & 22.5 & 25.4 \\
\hline Living in joint family & 20.0 & 11.1 & 24.6 & 15.0 & 20.4 \\
\hline \multicolumn{6}{|l|}{ Education $^{a}$} \\
\hline Up to intermediate & 57.2 & 40.7 & 65.5 & 51.4 & 59.6 \\
\hline Graduates & 22.9 & 27.8 & 18.3 & 26.3 & 21.8 \\
\hline Postgraduates & 14.3 & 16.7 & 10.5 & 11.3 & 11.7 \\
\hline \multicolumn{6}{|l|}{ Type of drivers ${ }^{a}$} \\
\hline Motorcyclists & 48.57 & 33.33 & 41.55 & 40.0 & 41.45 \\
\hline Car drivers & 34.28 & 55.56 & 35.21 & 50.0 & 40.73 \\
\hline Professional drivers & 17.14 & 11.11 & 22.53 & 10.0 & 17.45 \\
\hline \multicolumn{6}{|l|}{ Occupation type $^{d}$} \\
\hline Self-employed & 8.60 & 16.7 & 24.6 & 17.5 & 20.0 \\
\hline Part- or full-time employed & 37.1 & 27.8 & 41.5 & 22.5 & 34.5 \\
\hline Not working & 20.0 & 11.2 & 4.20 & 12.6 & 12.6 \\
\hline Student & 31.4 & 44.4 & 22.5 & 43.8 & 31.3 \\
\hline \multicolumn{6}{|l|}{ Occupation category $^{e}$} \\
\hline Government & 37.1 & 22.2 & 24.6 & 15.0 & 23.2 \\
\hline Private & 17.1 & 22.2 & 50.0 & 30.0 & 38.2 \\
\hline
\end{tabular}

${ }^{a}$ Not significant.

${ }^{b}$ Degrees of freedom $=9 ; N=257 ; X^{2}=23.145 ; p=.006$.

${ }^{c}$ Degrees of freedom $=6 ; N=257 ; X^{2}=15.305 ; p=.017$.

${ }^{d}$ Degrees of freedom $=27 ; N=257 ; X^{2}=52.714 ; p=.002$.

${ }^{e}$ Degrees of freedom $=12 ; N=275 ; X^{2}=34.539 ; p=.001$.

may have made them overconfident about their driving skills and less concerned about others' or their own safety. The total attitudinal score of the group made it the second most favorable road-safety-related attitude-holding group in the sample.

The second and smallest group of the study, opportunists, was different from the others because of drivers' highly unfavorable attitudes toward rule compliance and enforcement. Drivers in this group were likely to be affected by peer pressure. However, this group of drivers had the highest degree of regard for other road users. Probably, this was because of guilt or realization of their risk-taking nature, which makes other road users vulnerable to dangerous situations caused by that risk taking. Consequently, opportunistic drivers also realized the importance of careful driving. Therefore, such drivers encouraged safety measures such as keeping vehicles in good condition and avoiding using handheld mobile phones while driving; this might not only reduce the chance of conflict with other traffic but could potentially discourage him or her from taking a chance now and then to keep moving ahead. Overall, the group holds the least favorable attitudes toward road safety in the sample.
The third and largest group in the study are the regulators. Unlike the others, this group of drivers did not report strong associations on any of the attitudinal constructs. Highly favorable attitudes toward enforcement are the only exception. The only other noticeable dimension of the group, although not significant, was its tendency to break the rules. The explanation of these two contradicting attitudinal facets of the group might be found within their answers. It could be supposed that a regulator driver does not appreciate his or her tendency to break the rules and might think to overcome that tendency if stringent enforcement were applied on the roads. Thus, these facets are perhaps not wholly in contradiction because rules are fair only if enforced. The regulator group had the most favorable attitudes toward road safety, closely followed by the autonomous group. The post hoc multiple comparisons also revealed regulators to have significantly different attitudes from opportunists and from the risk averse.

Drivers in the fourth and second-largest group of the study, the risk averse, showed no concern about careful driving, did not value enforcement, and were highly likely to be affected by peer pressure. 
What made this group of drivers risk averse were their favorable attitudes toward complying with rules and their regard for personal safety, such as the use of seat belts or helmets and proper lights. It seemed that the group had a realization of the risks they were exposed to because of their careless nature and propensity to be influenced by the surrounding environment. Therefore, they tend to abide by the law to avoid risky encounters. These are the measures that can effectively counterbalance a driver's potential encounter with other traffic under peer pressure or through careless driving. The total AQ score of the group makes it the second most unsafe-attitude-holding group in the sample.

\section{Differences in Driving Behaviors of the Segments}

Evaluation of the groups' behaviors with the post hoc ANOVAs shows that drivers' attitudes toward road safety were reflected in their overall DBQ score; for example, the opportunists emerged as the most dangerous group and the regulators as the safest. However, although the groups showed strong associations on attitudinal constructs, the associations with reported driving behaviors were weak. Particularly for the autonomous drivers, who had a strong attitudinal profile, slight behavioral associations were noted. Only the opportunists had significant associations on all behavioral dimensions. One explanation of this phenomenon could be social desirability bias, which causes respondents to understate their negative behaviors (19). Another explanation could be a lack of accurate self-assessment of driving behaviors by drivers. As one of the studies about drivers in Pakistan suggested, they have a tendency to consider themselves safer drivers, particularly in comparison with other drivers (16). It seems that the phenomenon of optimism bias is applicable to Pakistani drivers; however, further empirical evidence is required to falsify or demonstrate this. Inspections of post hoc multiple comparisons suggested that the driving behaviors of the risk averse were closely comparable to those of the opportunists, although both groups had salient attitudinal characteristics. The groups reported high aberrant behaviors and loaded consistently on all the factors.

The discussion concluded that behaviors of drivers were found to be in agreement with their total attitudinal scores. The regulators emerged as holding the most favorable attitudes-behaviors toward road safety while the opportunists held the least. To be specific, the results suggest that attitude toward enforcement was the most powerful construct in defining and differentiating subgroups of Pakistani drivers. Interestingly, the groups' inclination toward the construct (either positive or negative) is also reflected in their total AQ scores. For example, favorable attitudes toward enforcement resulted in overall positive attitudes toward road safety and vice versa. These findings coincided with those from an earlier study carried out by the Shaheed Zulfiqar Ali Bhutto Institute of Science and Technology in Pakistan. The study reported that half of its respondents believed that a police presence on the roads forced them to respect traffic laws. And more than half said that speed cameras would improve traffic flow and reduce the number of traffic accidents (20).

\section{Sociodemographic Differences of the Segments}

Investigation of the sociodemographic composition of the segments helped to assess whether the variations in drivers' attitudes were attributable to their sociodemographic characteristics. The segments were found to have considerably varying sociodemographic characteristics. However, only a few statistically significant differences were noted on variables such as gender, income, occupation type, and occupation category. This suggested that the attitudinal dimensions of drivers, not sociodemographic characteristics, split them into different groups. This supports and strengthens the premise of this research in avoiding a priori classification, which has the potential to stereotype individuals.

It was also observed that opportunists and the risk averse shared not only a similar behavioral profile but also sociodemographic characteristics. For instance, both groups had a more or less similar composition on the gender and income variables. These groups of drivers were mostly affluent. In addition, despite being a smaller proportion of the sample (13.6\%), female drivers constituted one-third of both groups. This finding implied that the possibility that female drivers would drive dangerously cannot be ruled out. Support for this argument can also be found in the literature. For instance, it has been reported that "it's true that men do take more risks than women ... however, [women] are partaking in more risky behaviors than ever before. The gap is closing quickly" (21). Another study highlighted that female drivers in Pakistan are subject to unfair treatment by men and therefore may tend to behave aberrantly under peer pressure (16). The other notable features of the groups were the presence of young drivers, students, and degree holders, as well as single or separated or divorced individuals, in higher percentages than in the other groups. Opportunists and the risk averse also had the highest percentages of owning a house and driving a car, thus emphasizing their relative affluence.

Regulators and the autonomous, who emerged as groups holding relatively safer attitudes and behaviors, can also be compared to an extent on certain parameters, such as income. Both groups were predominantly composed of drivers from lower-income backgrounds. However, the regulators also had the highest percentage of middleincome group drivers. The finding thus suggests that drivers with lower or middle incomes were safer drivers than those with higher incomes. Support for this finding can also be drawn from the literature, which has linked higher income levels with aberrant behaviors such as speeding (22). However, care should be taken before generalizing the finding. More empirical research will definitely help to apply it across the board.

Apart from income, it was also noted that both these groups had a slightly higher percentage of mature drivers and a lower percentage of young drivers. It was therefore obvious that these groups would have full- or part-time employees and married individuals in higher percentages. The groups also showed a considerable proportion of individuals living in a joint family system as well as motorcyclists and professional drivers. The autonomous group's specific characteristics were the highest percentage of drivers who were unemployed or retired or looking after family and those who worked in the government sector. The group also had a good proportion of members who held academic degrees. In contrast, the regulators, specifically, had the lowest percentages of home-owning, female drivers, separated or divorced drivers, and degree holders in the sample. This group also had the highest percentage of drivers working in the private sector and with children at home.

The results led to the conclusion that the drivers' attitudes were influenced by their sociodemographic characteristics. The overall characteristics of the two groups that held relatively unsafe attitudesbehaviors led to the inference that being young, affluent, a student, and separated or divorced negatively affected attitudes and made drivers more dangerous on roads. It could be concluded that higher 
education levels did not guarantee low-risk driving behaviors, and neither did being female. These findings are not in agreement with a number of road safety studies. However, there are also studies that found that level of education (or being male or female) does not affect drivers' involvement in violations or crashes [e.g., Lourens et al. (23)].

\section{CONCLUSIONS}

This research provided a multitude of results. It suggested that the urban population of Pakistan has discrete attitudinal dimensions. That population can broadly be grouped into four clusters- the autonomous, opportunists, regulators, and the risk averse. The driving behaviors of these groups were found to be attributable to their attitudes, particularly those related to enforcement and careless driving. On the basis of the overall attitudinal and behavioral profiles of the segments, it could be concluded that the autonomous and regulators constituted a relatively safer category of drivers, compared with opportunists and the risk averse. Both opportunists and the risk averse are noted to be similar in terms of behavior and sociodemographic characteristics. The study further added that being young, a student, affluent, single, and divorced or separated negatively influenced drivers' attitudes. It also suggested that stereotyping only men as badly behaved drivers does not hold in Pakistan's case; female drivers were found to constitute one-quarter of the groups holding the most unfavorable attitudes.

This study also has analytical implications. For instance, the generation of discrete and statistically robust attitudinal and behavioral factors from the AQ and DBQ provided support for using the measures for future research in Pakistan. Another implication was the success of the attitudinal grouping of the drivers. This study supported the idea that, rather than simply aggregating drivers' responses or classifying them a priori, a segmentation technique is more useful to get collective and richer information about drivers in terms of multidimensional constructs.

\section{ACKNOWLEDGMENTS}

The lead author thanks Andrew Mark Tomlinson and Mojtaba Moharar for their helpful comments. The authors thank the anonymous reviewers for their comments and the Chartered Institution of Highways and Transportation, United Kingdom, and the University of Engineering and Technology in Lahore, Pakistan, for funding the research.

\section{REFERENCES}

1. Shah, S. G., K. Khoumbati, and B. Soomro. The Pattern of Deaths in Road Traffic Crashes in Sindh, Pakistan. International Journal of Injury Control and Safety Promotion, Vol. 14, No. 4, 2007, pp. 231-239.

2. Jacobs, G. D., and C.J. Baguley. Towards a Strategy for Improving Road Safety in Developing Countries. Overseas Centre Paper PA 3089/95. Transport Research Laboratory, Wokingham, Berkshire RG40 3GA, United Kingdom, 1995.
3. Evans, L. Traffic Safety and the Driver. Van Nostrand Reinhold, New York, 1991.

4. Ulleberg, P., and T. Rundmo. Personality, Attitudes, and Risk Perception as Predictors of Risky Driving Behavior Among Young Drivers. Safety Science, Vol. 41, No. 5, 2003, pp. 427-443.

5. Parker, D. Road Safety: What Has Social Psychology to Offer. In Traffic and Transport Psychology: Theory and Application (T. Rothengatter and R. D. Huguenin, eds.), Elsevier Ltd., Amsterdam, Netherlands, 2004.

6. Glendon, A. I. Driving Violations Observed: An Australian Study. Ergonomics, Vol. 50, No. 8, 2007, pp. 1159-1182.

7. Ajzen, I. Nature and Operation of Attitudes. Annual Review of Psychology, Vol. 52, 2001, pp. 27-58.

8. Anable, J. Complacent Car Addicts or Aspiring Enviromentalists? Identifying Travel Behavior Segments Using Attitude Theory. Transport Policy, Vol. 12, 2005, pp. 65-78.

9. Iversen, H., and T. Rundmo. Attitudes Towards Traffic Safety, Driving Behavior, and Accident Involvement Among the Norwegian Public. Ergonomics, Vol. 47, No. 5, 2004, pp. 555-572.

10. Chorlton, K. Understanding the Influences on Speed Choice. PhD dissertation. University of Leeds, 2007.

11. Ward, R. L., and R. J. Lancaster. International Review of the Individual Factors Contributing to Driving Behaviour and the Implications for Work-Related Road Safety. Behavioral Research in Road Safety: Thirteenth Seminar. Department of Transport, London, United Kingdom, 2003.

12. Carey, B. Fraud Case Seen as a Red Flag for Psychology Research. New York Times, Nov. 2, 2011.

13. Limpanitgul, T. Methodological Considerations in a Quantitative Study Examining the Relationship Between Job Attitudes and Citizenship Behaviors. Cardiff University, Soreze, France, 2009.

14. Hair, J.F. Multivariate Data Analysis. Pearson/Prentice Hall, Upper Saddle River, N.J., 2006.

15. Rowland, B., J. Davey, J. E. Freeman, and D. Wishart. Implementation of a Driving Diary Intervention to Reduce Aberrant Driving Behaviors. In Driving Assessment 2009: 5th International Driving Symposium on Human Factors in Driver Assessment and Design, University of Iowa, Iowa City, 2009, pp. 447-452.

16. Batool, Z., O. Carsten, and A. Jopson. Road Safety Issues in Pakistan: A Case Study of Lahore. Transportation Planning and Technology, Vol. 35, No. 1, 2012, pp. 31-48.

17. Parker, D., S. G. Stradling, and A. S. R. Manstead. Modifying Beliefs and Attitudes to Exceeding the Speed Limit: An Intervention Study Based on the Theory of Planned Behavior. Journal of Applied Social Psychology, Vol. 26, No. 1, 1996, pp. 1-19.

18. Lawton, R., D. Parker, A. S. R. Manstead, and S. G. Stradling. The Role of Affect in Predicting Social Behaviors: The Case of Road Traffic Violations. Journal of Applied Social Psychology, Vol. 27, No. 14, 1887, pp. $1258-1276$.

19. Hatfield, J., R. Fernandes, G. Faunce, and R. F. Soames Job. An Implicit Non-Self-Report Measure of Attitudes to Speeding: Development and Validation. Accident Analysis and Prevention, Vol. 40, No. 2, 2008, pp. 616-627.

20. Shaheed Zulfiqar Ali Bhutto Institute of Science and Technology. Survey: Pakistan Drivers Respect Cameras. http://www.traffictechnologytoday .com/news.php?NewsID=10424. Accessed Nov. 19, 2009.

21. Tannert, C. Who Are Better Drivers: Men or Women? 2009. http://cbsqc .blogspot.com/2012/06/who-are-better-drivers-men-or-women.html.

22. Shinar, D., E. Schechtman, and R. Compton. Self-Reports of Safe Driving Behaviors in Relationship to Sex, Age, Education, and Income in the U.S. Adult Driving Population. Accident Analysis and Prevention, Vol. 33, No. 1, 2001, pp. 111-116.

23. Lourens, P.F., J. Vissers, and M. Jesserun. Annual Mileage, Driving Violations, and Accident Involvement in Relation to Drivers' Sex, Age, and Level of Education. Accident Analysis and Prevention, Vol. 31, No. 5, 1999, pp. 593-597.

The Standing Committee on Vehicle User Characteristics peer-reviewed this paper. 